NASA/TM-2016-219383

\title{
Improving Power Density of Free-Piston Stirling Engines
}

Maxwell H. Briggs

Glenn Research Center, Cleveland, Ohio

Joseph M. Prahl and Kenneth A. Loparo

Case Western Reserve University, Cleveland, Ohio 


\section{NASA STI Program . . . in Profile}

Since its founding, NASA has been dedicated to the advancement of aeronautics and space science. The NASA Scientific and Technical Information (STI) Program plays a key part in helping NASA maintain this important role.

The NASA STI Program operates under the auspices of the Agency Chief Information Officer. It collects, organizes, provides for archiving, and disseminates NASA's STI. The NASA STI Program provides access to the NASA Technical Report Server-Registered (NTRS Reg) and NASA Technical Report ServerPublic (NTRS) thus providing one of the largest collections of aeronautical and space science STI in the world. Results are published in both non-NASA channels and by NASA in the NASA STI Report Series, which includes the following report types:

- TECHNICAL PUBLICATION. Reports of completed research or a major significant phase of research that present the results of NASA programs and include extensive data or theoretical analysis. Includes compilations of significant scientific and technical data and information deemed to be of continuing reference value. NASA counter-part of peer-reviewed formal professional papers, but has less stringent limitations on manuscript length and extent of graphic presentations.

- TECHNICAL MEMORANDUM. Scientific and technical findings that are preliminary or of specialized interest, e.g., "quick-release" reports, working papers, and bibliographies that contain minimal annotation. Does not contain extensive analysis.
- CONTRACTOR REPORT. Scientific and technical findings by NASA-sponsored contractors and grantees.

- CONFERENCE PUBLICATION. Collected papers from scientific and technical conferences, symposia, seminars, or other meetings sponsored or co-sponsored by NASA.

- SPECIAL PUBLICATION. Scientific, technical, or historical information from NASA programs, projects, and missions, often concerned with subjects having substantial public interest.

- TECHNICAL TRANSLATION. Englishlanguage translations of foreign scientific and technical material pertinent to NASA's mission.

For more information about the NASA STI program, see the following:

- Access the NASA STI program home page at http://www.sti.nasa.gov

- E-mail your question to help@sti.nasa.gov

- Fax your question to the NASA STI Information Desk at 757-864-6500

- Telephone the NASA STI Information Desk at 757-864-9658

- Write to:

NASA STI Program

Mail Stop 148

NASA Langley Research Center Hampton, VA 23681-2199 
NASA/TM-2016-219383

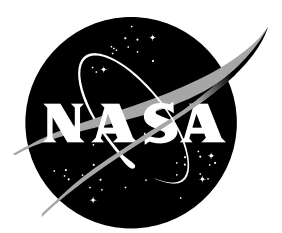

\section{Improving Power Density of Free-Piston Stirling Engines}

Maxwell H. Briggs

Glenn Research Center, Cleveland, Ohio

Joseph M. Prahl and Kenneth A. Loparo

Case Western Reserve University, Cleveland, Ohio

Prepared for the

14th International Energy Conversions Engineering Conference (IECEC) sponsored by the American Institute of Aeronautics and Astronautics Salt Lake City, Utah, July 25-27, 2016

National Aeronautics and

Space Administration

Glenn Research Center

Cleveland, Ohio 44135 
This report contains preliminary findings, subject to revision as analysis proceeds.

Level of Review: This material has been technically reviewed by technical management.

Available from

NASA STI Program

Mail Stop 148

NASA Langley Research Center

Hampton, VA 23681-2199
National Technical Information Service 5285 Port Royal Road Springfield, VA 22161

703-605-6000

This report is available in electronic form at http://www.sti.nasa.gov/ and http://ntrs.nasa.gov/ 


\title{
Improving Power Density of Free-Piston Stirling Engines
}

\author{
Maxwell H. Briggs \\ National Aeronautics and Space Administration \\ Glenn Research Center \\ Cleveland, Ohio 44135 \\ Joseph M. Prahl and Kenneth A. Loparo \\ Case Western Reserve University \\ Cleveland, Ohio 44106
}

\begin{abstract}
Analyses and experiments demonstrate the potential benefits of optimizing piston and displacer motion in a free-piston Stirling Engine. Isothermal analysis shows the theoretical limits of power density improvement due to ideal motion in ideal Stirling engines. More realistic models based on nodal analysis show that ideal piston and displacer waveforms are not optimal, often producing less power than engines that use sinusoidal piston and displacer motion. Constrained optimization using nodal analysis predicts that Stirling engine power density can be increased by as much as 58 percent using optimized higher harmonic piston and displacer motion. An experiment is conducted in which an engine designed for sinusoidal motion is forced to operate with both second and third harmonics, resulting in a piston power increase of as much as 14 percent. Analytical predictions are compared to experimental data and show close agreement with indirect thermodynamic power calculations, but poor agreement with direct electrical power measurements.
\end{abstract}

\subsection{Introduction}

Stirling engines can achieve high thermal efficiency (net work out/heat in) but have low power density (power per unit volume) when compared to many open-cycle engines (Refs. 1, 2, and 3). One potential method of increasing power density is to enforce piston and/or displacer motion that more closely approximate those of the ideal Stirling cycle. Achieving the ideal cycle requires that the piston and displacer dwell and abruptly change direction throughout the cycle, which is difficult to achieve in both kinematic and free-piston configurations. Designers typically sacrifice ideal motion for practically achievable motion, most often converging on a mechanical linkage or electrical control scheme that imposes sinusoidal or nearly sinusoidal motion (Refs. 4, 5, and 6). While there are certainly benefits to choosing sinusoidal motion, it is not the optimal choice since sinusoidal motion reduces power density. There are some patents based on achieving piston motion that more closely approximates ideal motion in kinematic Stirling engines (Refs. 7 and 8), but the author has not found any examples of a functional kinematic Stirling which uses non-sinusoidal motion for the purpose of improving performance and no examples of attempts to achieve performance benefits through non-sinusoidal motion on free-piston Stirling engines.

Stirling cycle applications include cryo-coolers (Refs. 9 and 10), natural gas co-generation units (Refs. 11, 12, and 13), solar-dynamic power conversion (Refs. 14, 15, and 16), and nuclear dynamic power conversion (Refs. 17 to 21). They are typically used in applications which have high fuel costs or in systems that require closed-cycle operation. High efficiency and closed-cycle operation are both 
requirements of space power systems, making free-piston Stirling engines candidates for these applications. They are a key technology in NASA's Radioisotope Power System program because their high efficiency potentially enables NASA to increase the number of missions it can fly over the coming decades using the limited supply of plutonium-238 (Refs. 20, 21, and 22). They also trade favorably in low to moderate power level fission power applications because their high efficiency requires less heat input from the reactor and reduces heat rejection requirements, reducing the mass of the reactor shield and the radiators (Refs. 17, 18, 19, and 23). Stirling engines have been considered for use in several terrestrial applications including automotive engines, concentrated solar power plants, and residential co-generation systems, especially when rising fossil fuel costs indicate that their high efficiency can make them economical. However, the low power density and high cost of Stirling engines typically make them unpractical when fuel costs are low and internal combustion or other open-cycle engines are viable.

Figure 1 shows a schematic of the ideal piston and displacer position for a Stirling engine in the beta configuration. Process 1-2 shows constant temperature compression, in which the displacer remains still, minimizing the expansion space volume. The piston compresses the gas as heat is removed through the cooler. Process 2-3 shows constant volume heat addition, in which the displacer moves gas from the cold side to the hot side, through the regenerator, while the piston remains still. Process 3-4 is a constant temperature expansion process, in which the expansion of the gas moves the piston, and the displacer moves along with it to minimize volume of the compression space. The work done during the expansion process minus the work done during the compression process is the usable energy produced by the Stirling cycle. In free-piston engines this power is typically extracted through the linear alternator. Process 4-1 is a constant volume heat removal process in which the displacer moves gas from the hot to the cold side, through the regenerator, while the piston remains still. For an ideal Stirling engine, as the regenerator effectiveness approaches unity the external heat addition and rejection requirement during the constant volume processes approaches zero, and the Stirling cycle efficiency approaches the Carnot efficiency. The power density of an ideal Stirling engine with zero dead volume is independent of regenerator effectiveness and is proportional to the natural log of the volume ratio.

Ideal piston and displacer motion requires the piston and displacer to dwell during periods within a cycle and abruptly change direction during others, requiring large forces. The commonly used alternative to ideal motion is sinusoidal motion, which can be analyzed under isothermal assumptions using the method proposed by Gustav Schmidt (Ref. 24). Isothermal engines with perfect regeneration operating under the Schmidt cycle achieve the same efficiency as the ideal Stirling engine, which is equal to the Carnot efficiency. The sinusoidal piston motion associated with the Schmidt cycle, however, does reduce power density.

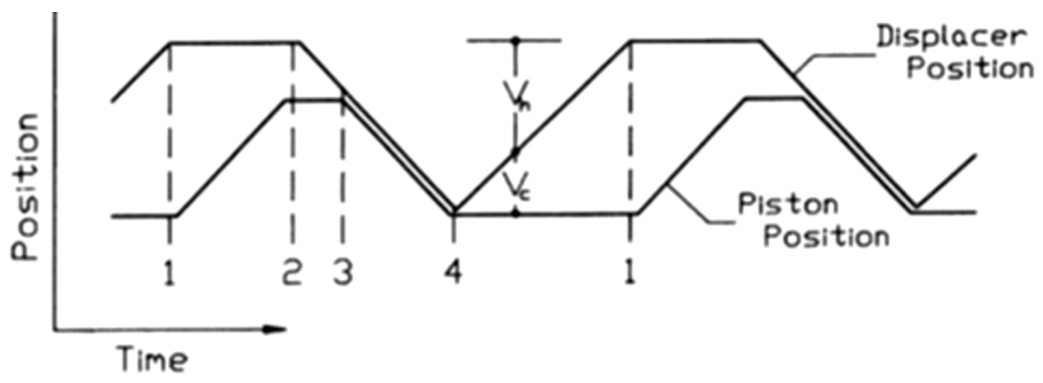

Figure 1.-Piston and displacer waveforms for the ideal Stirling cycle. 
Specific Power Ratio for $\tau=\mathbf{2 . 5}$

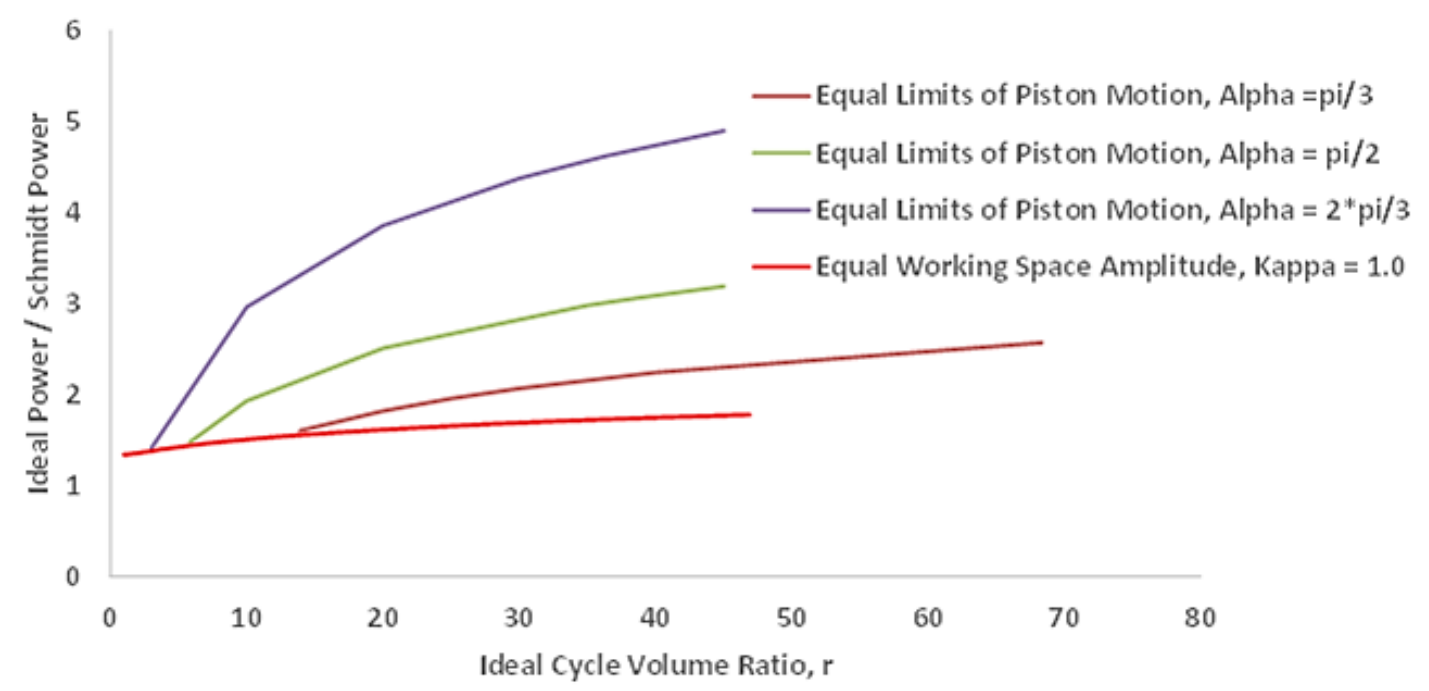

Figure 2.-Comparison of power density ratio for ideal and Schmidt cycles assuming equal limits of piston motion or equal working space amplitude

Isothermal analysis of the ideal and Schmidt cycles shows the extent to which theoretical power density can be improved through the use of ideal motion. Figure 2 shows the ratio of ideal to Schmidt cycle power assuming equal limits of piston motion or equal working space amplitudes. The complete analysis is shown in Briggs (Ref. 25) with major points highlighted below.

$$
\begin{array}{r}
W_{\text {net,ideal }}=m R T_{C S}\left[\tau \ln \left(\frac{r+K_{d}\left(\tau \tau_{d}-1\right)}{1+K_{d}\left(\tau \tau_{d}-1\right)}\right)-\ln \left(\frac{r+K_{d}\left(\tau_{d}-1\right)}{1+K_{d}\left(\tau_{d}-1\right)}\right)\right] \\
r=\frac{V_{\max }}{V_{\min }} \tau=\frac{T_{E S}}{T_{C S}} K_{d}=\frac{V_{D}}{V_{\min }} \tau_{d}=\frac{T_{C S} C_{1}}{V_{D}} \\
C_{1}=\left(\frac{V_{C S, c l}}{T_{C S}}+\frac{V_{C}}{T_{C}}+\frac{V_{R}}{T_{E f f R}}+\frac{V_{H}}{T_{H}}+\frac{V_{E S, c l}}{T_{E S}}\right) \\
W_{\text {Schmidt }}=2 \pi m R T_{C S}\left(\frac{\tau \kappa}{K_{t}^{2}}\right)\left(\frac{1-\sqrt{1-b^{2}}}{b^{2} \sqrt{1-b^{2}}}\right)(\tau-1) \sin \alpha \\
b=\frac{\sqrt{\tau^{2}+2 \kappa \tau \cos (\alpha)+\kappa^{2}}}{K_{t}} \\
\kappa=\frac{V_{E S, s w}}{V_{C S, s w}} K_{t}=\frac{2 T_{E S} C_{2}}{V_{C S, s w}} \\
C_{2}=\left(\frac{V_{C S, s w}}{2 T_{C S}}+\frac{V_{C S, c l}}{T_{C S}}+\frac{V_{C}}{T_{C}}+\frac{V_{R}}{T_{E f f} R}+\frac{V_{H}}{T_{H}}+\frac{V_{E S, c l}}{T_{E S}}+\frac{V_{E S, s w}}{2 T_{E S}}\right)
\end{array}
$$


where $m$ is the working gas mass, $R$ is the specific gas constant, $T$ is the temperature of a given gas space, and $V$ is the volume of a given gas space. The subscript max refers to the maximum cycle value, min refers to the minimum cycle value, $E S$ refers to the expansion space value, $C S$ refers to the compression space value, $D$ refers to the dead space value, $C$ refers to the cooler space value, $c l$ refers to clearance volumes, $r$ refers to regenerator values, $H$ refers to heater values, and $s w$ refers to swept volumes

\subsection{Analysis}

\subsection{Nodal Analysis—Sage Stirling Analysis Software}

Isothermal analysis assumes that heat transfer rates in the expansion and compression spaces are so high that the temperature of the gas within those volumes can be considered isothermal. Real engines lack sufficient surface area in the compression and expansion spaces to accomplish this, so high surface area heaters/acceptors and coolers/rejectors are added along with their associated dead volume.

Improving model accuracy beyond what is achievable with isothermal or adiabatic analysis requires nodal analysis and a specific engine design, including heat exchanger geometry, regenerator specifications, cylinder geometry, seal geometry, etc. One such nodal analysis tool is a commercially available program called Sage (Ref. 26). Sage is commonly used for Stirling engine optimization in the design phase. The Sage is a one-dimensional, cyclic steady-state model that couples the equations of motion of the piston and displacer with the Navier-Stokes equations and energy equations. Sage can also be used to calculate the reduction in available energy, which is ignored by isothermal and adiabatic analysis.

Sage is used to model a 1-kW Stirling engine which is representative of engines tested at GRC. This model assumes an isothermal boundary condition on a solid surface node within the engine, it then calculates temperature gradients in the rest of the solid and the gas based on solid conduction and calculated convection coefficients. The axial temperature distribution along the base of the finned exchangers (acceptor and rejector) are set as an input. These temperature inputs typically come from heat transfer analysis done outside of Sage. Sage then iteratively solves for gas temperatures and pressure drops by guessing and checking fin temperature profiles and gas velocities and the resulting displacer motion (piston motion is typically a user input).

The predicted power output for isothermal analysis is 36 percent larger than the Sage predicted power output. Isothermal analysis predicts an engine efficiency equal to the Carnot efficiency, which in this case is $0.550\left(T_{h}=779{ }^{\circ} \mathrm{C}\right.$ and $\left.T_{c}=350{ }^{\circ} \mathrm{C}\right)$ which is 80 percent higher than the efficiency of 0.307 predicted by Sage, suggesting that isothermal analysis does a relatively poor job of predicting the heat transfer requirements in real engines.

Sage requires all non-sinusoidal time dependent inputs to be entered as sums of harmonic sinusoids. As higher harmonics are added, the solver time resolution must be increased to resolve the higher frequencies, increasing computational time. Ideal piston and displacer motion are approximated using 7term truncated Fourier series ( $\mathrm{R}^{2}$ values for all cases run are above 0.995).

One inherent problem in modeling ideal piston and displacer motion in Sage or any other high fidelity Stirling model is that there are in infinite combination of piston and displacer motions which are considered ideal. Piston motion can be symmetric or asymmetric, with varying dwell times and many combinations of dwells or piston/displacer constraint methods are still considered ideal. Since isothermal analysis assumes that heat transfer takes place instantaneously and does not take into account pressure drop or other loss mechanisms that are functions of piston and displacer velocity, predicted power output is equal for all ideal waveforms and the efficiencies each of these waveforms are equal to the Carnot efficiency, regardless of dwell times or piston/displacer velocities. However, higher fidelity tools such as 
Sage consider the effect of insufficient dwell times on gas temperatures and higher mass flow rates on pressure drop through the regenerator and heat exchangers, so they predict that different versions of the ideal waveform have different power output and efficiency.

\subsection{Nodal Analysis-Comparison of Sinusoidal and Ideal Waveforms}

In this section nodal analysis is used to compare performance of ideal waveforms with sinusoidal waveforms. The ideal motion examined in this section requires external forcing on the piston and displacer. In reality, most free-piston Stirling engines have a free displacer attached to a linear spring which resonates near the convertor operating frequency. These engines have no mechanism to impose an ideal waveform on the displacer. However, kinematic Stirling engines and some unproven free-piston designs do have mechanisms to impose non-sinusoidal displacer waveforms. The analysis in this section is intended to show the effect of ideal piston and displacer motion on engines designed with such capability. Engines operating with non-sinusoidal piston and displacer motion are compared to an engine operating with a sinusoidal piston and a free displacer.

Ideal piston and displacer motion result in maximum power density and efficiency in ideal Stirling engines. In real engines, increased piston and displacer velocities inherent to ideal waveforms can adversely affect engine performance by increasing pressure drop through heat exchangers and/or adversely affecting heat transfer. The following analysis shows that these parasitic effects overwhelm the increase in thermodynamic power provided by ideal waveforms when applied to this engine geometry.

This analysis constrains the maximum and minimum working volume, minimum expansion space volume, and minimum compression space volume to the same values as sinusoidal motion. These constraints limit the inward travel of the piston and displacer, leaving a stagnant gas volume in the compression space and limiting the working space stroke. Figure 3 shows a comparison of ideal and sinusoidal motion under these constraints. Isothermal analysis predicts that under these constraints the power density of an engine operating with ideal piston and displacer motion is 50 percent higher than the

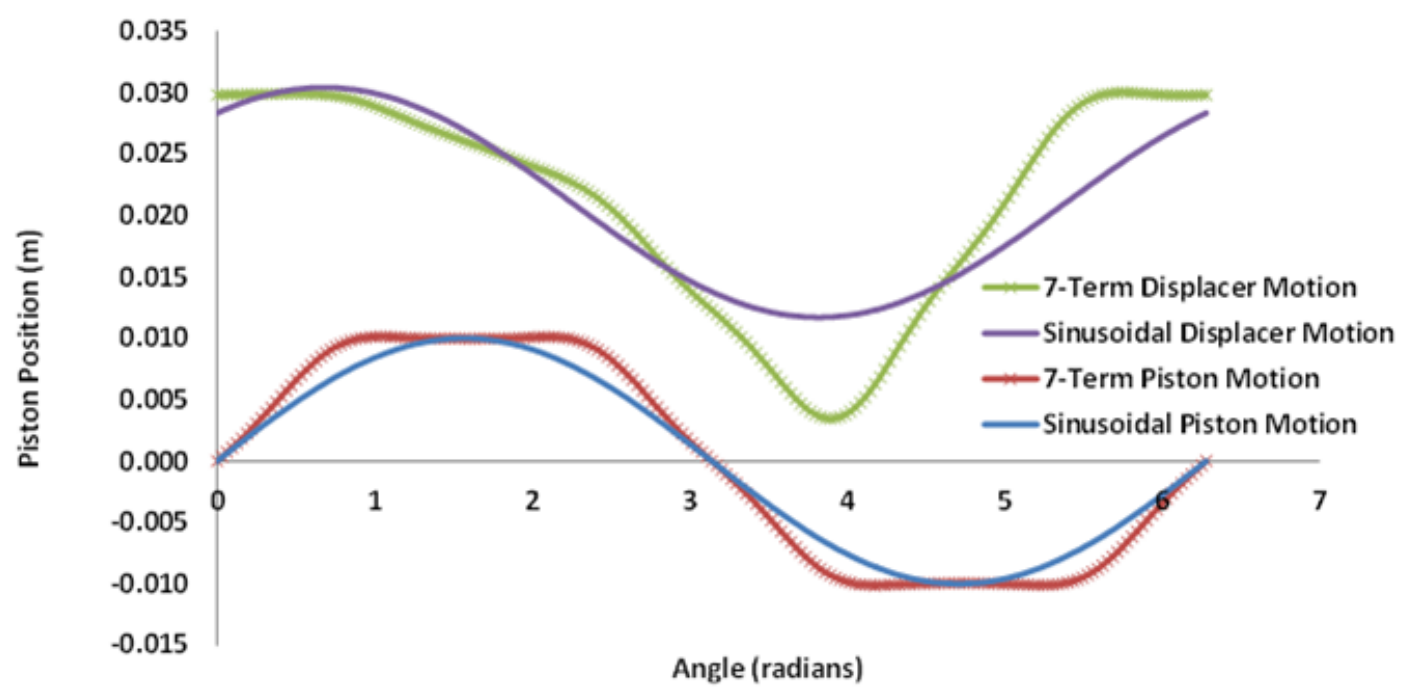

Figure 3.-Comparison of ideal and sinusoidal motion assuming equal minimum spacing between piston and displacer. 
TABLE I.-NODAL ANALYSIS RESULTS FOR IDEAL WAVEFORMS

\begin{tabular}{|l|c|c|c|c|}
\hline & $\begin{array}{c}\text { Net power, } \\
\text { W }\end{array}$ & $\begin{array}{c}\text { Piston power, } \\
\text { W }\end{array}$ & $\begin{array}{c}\text { Displacer power, } \\
\text { W }\end{array}$ & $\begin{array}{c}\text { Efficiency, } \\
\%\end{array}$ \\
\hline Sinusoidal & 1170 & 1170 & 0 & 30.7 \\
\hline $\begin{array}{l}\text { Symmetric } \\
\text { dwell }=\pi / 4\end{array}$ & 50 & 1680 & 1630 & 1.2 \\
\hline $\begin{array}{l}\text { Symmetric } \\
\text { dwell }=\pi / 2\end{array}$ & 820 & 1580 & 760 & 16.5 \\
\hline $\begin{array}{l}\text { Symmetric } \\
\text { dwell }=3 \pi / 4\end{array}$ & 630 & 1320 & 690 & 12.7 \\
\hline $\begin{array}{l}\text { Asymmetric } \\
\text { min velocity }\end{array}$ & 1150 & 1580 & 430 & 21.8 \\
\hline
\end{tabular}

same engine operating with sinusoidal piston and displacer motion, with no change in efficiency Reference 25. Sage-based nodal analysis of ideal motion under these constraints is more pessimistic, predicting lower power density and efficiency than predicted for sinusoidal motion in most cases.

Four versions of the ideal Stirling piston/displacer waveform are selected for study, three symmetric piston waveforms with varying piston dwell times and one asymmetric waveform in which the piston dwell times are selected by minimizing the piston and displacer RMS velocity in an effort to reduce pressure drop losses through the regenerator. The results of nodal analysis applied to these waveforms appears in Table I.

Regardless of dwell time, symmetric ideal waveforms operating under the constraints of Case 1 produce less power and are less efficient than an engine operating with sinusoidal piston motion and free displacer motion. This is due to the increased viscous dissipation in the regenerator and heat exchangers caused by increasing piston and/or displacer velocity. The medium dwell case is the best of the three symmetric cases examined, but it offers no improvement over sinusoidal motion. Removing the symmetry constraint on ideal waveforms allows the piston and displacer to achieve ideal motion with lower velocities, allowing for improved engine performance. This is a coarse analysis of the dependence of engine performance on piston dwell time, and it is likely that an optimum performance point exists at dwell time between the points chosen for analysis above. It is possible that some version of the ideal waveform could show an increase in power density over sinusoidal motion, but the results of this analysis suggest that replacing sinusoidal waveforms with ideal waveforms most likely does not produce a combination of power and efficiency that sufficiently improves on sinusoidal motion to justify implementation.

\subsection{Optimized Waveforms}

It may seem discouraging that under the chosen constraints there is no benefit to achieving ideal motion for this engine design. However, seeing that ideal motion results in increased piston power in all cases suggests that there may exist some optimal motion, different from ideal motion, that takes advantage of the increased piston power without incurring large penalties due to increased viscous losses through the regenerator and heat exchangers. Determining this optimum motion requires the use of nonlinear constrained optimization. This is achieved using the fmincon function in MATLAB, using net power, as predicted by Sage, as the objective function. Various non-linear constraints can be used depending on how one wants to match sinusoidal and optimal waveforms. In all cases the out-limits of piston and displacer motion are set equal to the values generated in the sinusoidal case, guaranteeing that 
the engine does not have to grow to accommodate ideal motion. The following cases are studied in which different characteristics of the sinusoidal waveform are used as optimization constraints:

1. In-limit of piston equal, minimum piston/displacer gap equal

2. In-limit of piston equal, no limit on displacer inward travel

3. No constraint on the in-limit of piston or displacer motion

The optimization uses a seven term Fourier series to define the piston and displacer waveforms, giving 27 independent variables (seven piston amplitudes, six piston phase angles with the phase angle of the fundamental frequency is fixed at zero, seven displacer amplitudes, seven displacer phase angles). Using single term sinusoidal motion as starting point, optimization requires hundreds of iterations and thousands of function evaluations. Each function evaluation requires a converged Sage solution, making the optimization a computationally intensive process. The optimization results are summarized in Table II.

In each case the optimized waveform produces more power at reduced efficiency than the sinusoidal case, opening a viable trade space between power and efficiency for engine designers. Figure 4 compares sinusoidal and optimized piston/displacer motion, piston force displacement diagram, and displacer force displacement diagram for Case 2. The complete dataset can be found in Reference 25.

This optimization uses only power output in the objective function. An alternative would be to optimize on a weighted combination of power and efficiency in which the weights are chosen according to the specific application, however a full mapping of the power/efficiency trade space is, as yet, unstudied.

\subsection{Experimental Testing}

The numerical analysis above suggests that Stirling engine power density and efficiency can be traded against each other and specified to the designer's needs. This section describes a test performed in the Stirling Research Lab (SRL) at the NASA Glenn Research Center intended to verify that non-sinusoidal piston motion is achievable and to verify the predictions of nodal analysis.

The engines chosen for testing are a pair of 1-kW engines previously used to test a sodium-potassium (NaK) heat exchanger (Ref. 27) and to test the feasibility of operating two engines with a common expansion space (Ref. 28) for the Fission Surface Power project. The specific cases studied above could not be replicated with these engines because they have no method of altering the displacer waveform. Therefore only the piston waveform is altered and the displacer freely responds to the resulting changes in the pressure wave. In practice the stiff linear spring attached to the displacer results in nearly sinusoidal displacer motion in all cases.

TABLE II.-NODAL ANALYSIS RESULTS FOR OPTIMIZED WAVEFORMS

\begin{tabular}{|l|c|c|c|c|}
\hline & $\begin{array}{c}\text { Net power, } \\
\text { W }\end{array}$ & $\begin{array}{c}\text { Piston power, } \\
\text { W }\end{array}$ & $\begin{array}{c}\text { Displacer power, } \\
\text { W }\end{array}$ & $\begin{array}{c}\text { Efficiency, } \\
\%\end{array}$ \\
\hline Sinusoidal & 1170 & 1170 & 0 & 30.7 \\
\hline Case 1 & 1430 & 1580 & 150 & 27.9 \\
\hline Case 2 & 1630 & 1730 & 100 & 26.6 \\
\hline Case 3 & 1850 & 1853 & 3 & 25.3 \\
\hline
\end{tabular}




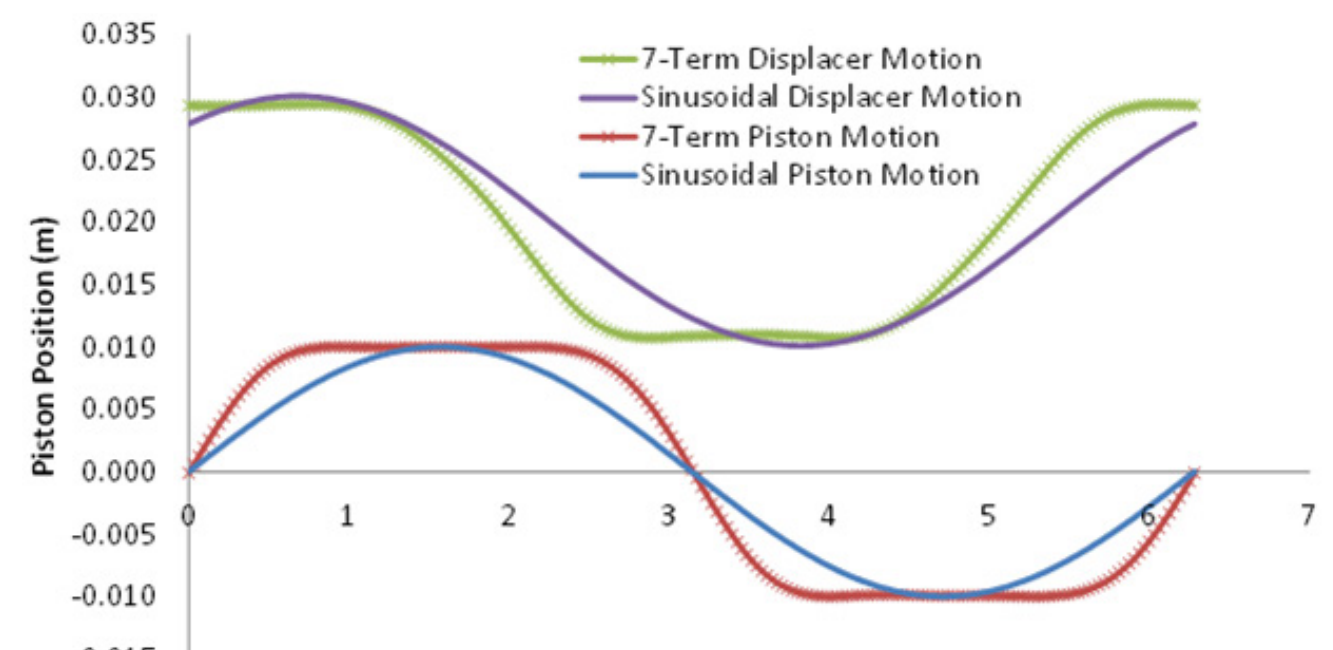

$-0.015$

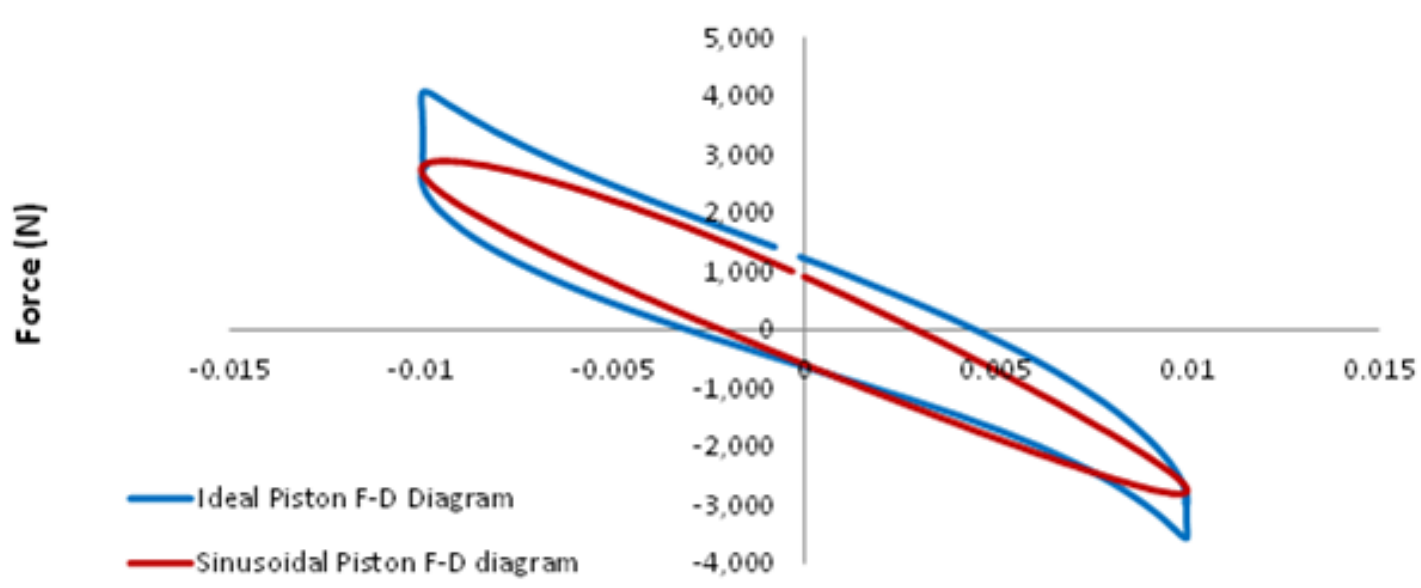

Displacement (m)

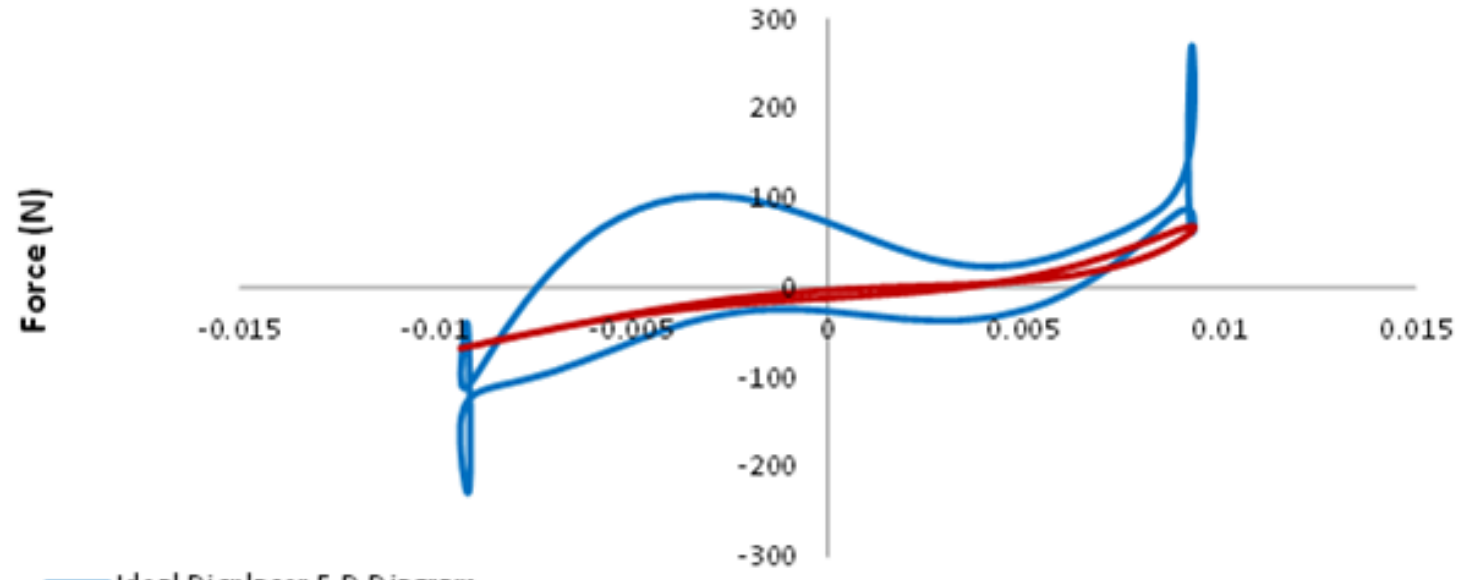

—Ideal Displacer F-D Diagram

- Sinusoidal Displacer F-D diagram Displacement (m)

Figure 4.-Comparison of Sage results for sinusoidal and optimized waveforms under Case 2 constraints. 
Since the piston is not designed to resonate at higher harmonics, higher harmonic motion had to be imposed by the alternator, increasing the spring force required from the alternator and the alternator current. The current required to run non-sinusoidal piston waveforms at the nominal operating amplitude of $10 \mathrm{~mm}$ saturates the alternator before the waveforms can be substantially altered. However, measurable changes in piston motion and engine performance can be achieved when operating at reduced amplitude. Six millimeter is chosen as the baseline for the experiment because it is the minimum recommended amplitude required to charge the internal gas bearings. Alternatively, if an engine were available that was designed for multi-harmonic resonance the alternator force would be reduced and greater amplitudes could be achieved and alternator losses could be minimized.

The out-limit of piston motion for all tests is set equal to the value measured during sinusoidal testing. The first harmonic of the piston amplitude is then increased and additional harmonics are added until the out-limit of piston motion returns to the value measured during $6 \mathrm{~mm}$ baseline testing. The non-sinusoidal piston waveforms are allowed to exceed the in-limit of piston motion, consistent with constraint Case 3.

Non-sinusoidal piston waveforms can be obtained using a programmable AC source to impose an arbitrary voltage waveform on the alternator terminals. However, the current requirements of this method is prohibitive. Instead, three AC sources are connected in series, each dedicated to a single harmonic and paralleled to a capacitor bank. This method reduces the current requirement of the AC sources, but also limits the number of harmonics that can be tested due to manufacturer limits on the number of AC sources that can be put in series.

Alternator inductance causes the voltage measured at the alternator terminals to be larger than the EMF and out of phase with the alternator current (even when the engines are operated at resonance). In single harmonic engines, a tuning capacitor can be used to compensate for the alternator inductance so that the controller voltage is reduced to the level of the EMF and the current and "post-capacitor" voltage are once again in phase. However, when additional harmonics are introduced, the tuning capacitor cannot cancel the alternator inductance of the higher harmonics so the voltage required of the control system is much higher than the EMF seen by the piston. There may be an alternative solution to this problem involving changes to the control system electronics, but this experiment used the "brute force" approach, in which the AC sources used as the control system supply relatively large voltages in order to impose relatively small piston EMF. For example, a peak-to-peak third harmonic voltage of $420 \mathrm{~V}$ results in an estimated peak-peak EMF of $30 \mathrm{~V}$ (estimated EMF based on piston velocity measurements times the motor constant).

The methods used in this experiment are not ideal for demonstrating system level benefits of nonsinusoidal waveforms on Stirling engines. However, the intent of this experiment is to achieve a proof-ofconcept on existing and available hardware and provide an experimental database for comparison to model predictions. Sophistication and optimization of the overall engine and control system is left as future work.

Heat input is provided using cartridge heaters capable of delivering $4 \mathrm{~kW}$ of power to each engine. Voltage to each of these heaters is regulated using a Variac. Each engine uses a separate Variac so that the average hot-end temperatures of the engines can be made equal despite heater cartridge variability and differences in thermal resistance between the cartridges and the engines. Heater power is measured and is used to calculate gross engine efficiency. The cold end of the engine is water cooled using a recirculating water chiller.

Piston and displacer motion are measured using Fast Linear Displacement Transducers (FLDT). Alternator current is measured using a Pearson coil on each engine. The FLDT signals are read into an oscilloscope to capture the waveforms in real time. A high precision power meter, which is also capable of recording waveforms, is used to measure alternator current and pre-capacitor voltage. The post- 
capacitor voltage and alternator current are read by a separate oscilloscope. Both oscilloscopes and the power meter are synchronized using the piston FLDT signal to guarantee proper phasing during postprocessing of the data.

Hot-end temperature on the engine is measured using eight type $\mathrm{K}$ thermocouples. Cooling water temperature on each engine is measured using eight platinum RTDs (four each on inlet and outlet). Alternator housing temperature and bounce space gas temperature are also measured using four thermocouples on each engine.

Steady-state measurements are taken at a rate of $1 \mathrm{~Hz}$. Higher speed data, on the order of $\mathrm{kHz}$ are taken using the oscilloscopes and power meter described above.

\subsection{Methodology}

Each test begins by establishing a steady-state baseline at $6 \mathrm{~mm}$ amplitude, $550{ }^{\circ} \mathrm{C}$ hot-end temperature and $50^{\circ} \mathrm{C}$ cold-end temperature. The baseline point uses only the first harmonic power supply, producing sinusoidal piston motion, which is the typical operating mode of free-piston Stirling engines. This point is used to establish both the baseline power measurement and the out-limit of piston motion which is matched by all non-sinusoidal waveforms. At the conclusion of baseline testing the AC Bus voltage of the second or third harmonic is increased by $45 \mathrm{~V}$ at a phase angle of $180^{\circ}$ relative to the $50 \mathrm{~Hz}$ AC Bus voltage. This results in a decrease in the out-limit of piston motion as the bottom of the waveform flattens. The out-limit of piston motion is then returned to the baseline value by increasing the voltage of the $50 \mathrm{~Hz}$ AC Bus. Heater power is then increased to maintain a hot-end temperature of $550{ }^{\circ} \mathrm{C}$. This process is then repeated until some limit is reached. While the AC Bus increment of $45 \mathrm{~V}$ results in a relatively coarse test matrix, it is chosen because this increment results in a measurable change in the out-limit of piston motion for both the second and third harmonics. Smaller increments could be used if the piston position measurement was made more precise and repeatable from cycle to cycle. Throughout testing the baseline point is revisited to establish repeatability and to verify that the lower limit of piston motion has not changed. Numerical optimization, using the Sage nodal analysis tool, identifies phase angles of $-\pi / 2$ for the second harmonic and zero for the third harmonic as optimizing power output. These are the only phase angles tested in this test experiment. Exploration of phase angle sensitivity and influence on other parameters such as efficiency is left to future work.

Although the control system is capable of providing 850 Vrms to the alternator, engine or alternator limits are reached well before these voltages are achieved. Testing beyond 160 Vrms on the second harmonic results in unbalanced current between engines, erratic power measurement, and eventually an overstroke protection circuit trip, resulting in engine stall. This could be an indication of alternator saturation, but it is well below the engine manufacturer's prescribed limits on the alternator voltage and current. This instability is repeatable and limits the second harmonic test matrix to 160 Vrms. Testing beyond 295 Vrms on the third harmonic results in an audible and abnormal noise coming from the engine. This noise is not consistent with any type of impact, whether piston-displacer or piston-endstop, and could be benign. However, testing beyond $295 \mathrm{Vrms}$ on the third harmonic is avoided in an effort to preserve the engines. When operating with both the second and third harmonics simultaneously, a similar noise is heard when the third harmonic voltage is increased beyond 105 Vrms. These engine/alternator/control constraints established the operational limits for non-sinusoidal testing.

This experiment aims to compare the thermodynamic power output of free-piston engines operating with several different piston waveforms. The engines could not be modified for dynamic pressure measurement within budget and time constraints, so it is not possible to produce true P-V diagrams based on direct measurements. However, there are several methods of calculating thermodynamic power output

based on measured parameters such as alternator power, alternator voltage, alternator current, alternator 
resistance, and piston position. The most direct power measurement is taken by time averaging of the instantaneous alternator voltage (pre-capacitor) multiplied by the instantaneous current at the alternator terminals. This measurement is made using the internal algorithms of the power meter as well as through post-processing of the voltage and current waveforms. Adding the resistive losses of the alternator to this measurement gives an approximation of the thermodynamic power of the engine.

This method is useful for determining average power output of the engines, and is used as the figure of merit in Section 3.2 ,Results. However, due to the alternator inductance it does not give good information on the instantaneous piston power or forces, making it less useful for the purposes of model comparison. Instantaneous power can be calculated by multiplying the measured current by the EMF calculated by multiplying the piston velocity by the motor constant. The time average of this quantity gives an alternate measure of thermodynamic power output of the engine.

\subsection{Results}

The operating conditions for the baseline case are $550{ }^{\circ} \mathrm{C}$ hot-end temperature, $50{ }^{\circ} \mathrm{C}$ cold-end temperature, and $6 \mathrm{~mm}$ piston amplitude. The out-limit of piston motion under these conditions is $6.06 \mathrm{~mm}$. The measured out-limit of piston motion is kept constant throughout higher harmonic testing. Table III summarizes the various power measurements and calculations described in Section 3.1, Methodology, as well as efficiency. The gross efficiency measured during testing is calculated by dividing the piston power (alternator power plus resistive losses) by the gross heat input (electric power supplied to the cartridge heaters). The gross heat input includes heat that is lost through the engine insulation package, so it underpredicts thermodynamic efficiency. The efficiency calculated by Sage is based on the net heat input, including only the heat that enters the acceptor of the engine. These values are not directly comparable, and are not used for model validation, but are included for reference.

TABLE III.-MEASURED AND CALCULATED ENGINE PERFORMANCE

\begin{tabular}{|c|c|c|c|c|c|}
\hline & $\begin{array}{c}\text { Alt power } \\
+ \\
\text { resistive loss, } \\
\text { W }\end{array}$ & $\begin{array}{c}\text { I*VEMF } \\
\text { power, } \\
\text { W }\end{array}$ & $\begin{array}{l}\text { Sage predicted } \\
\text { power, } \\
\text { W }\end{array}$ & $\begin{array}{c}\text { Gross efficiency, } \\
\%\end{array}$ & $\begin{array}{c}\text { Net efficiency, } \\
\%\end{array}$ \\
\hline & Measured & Calculated & Prediction & Measured & Sage \\
\hline Sinusoidal & 435 & 467 & 457 & 26.2 & 33.2 \\
\hline $45 \mathrm{~V}$ 2nd & 463 & 502 & 504 & 25.8 & 33.6 \\
\hline $90 \mathrm{~V} \mathrm{2^{ \text {nd } }}$ & 488 & 550 & 552 & 25.0 & 33.7 \\
\hline $110 \mathrm{~V}^{\text {nd }}$ & 487 & 567 & 580 & 24.3 & 33.9 \\
\hline $45 \mathrm{~V}^{\text {rd }}$ & 449 & 482 & 476 & 26.1 & 33.4 \\
\hline $90 \mathrm{~V}^{\text {rd }}$ & 452 & 501 & 491 & 25.7 & 33.5 \\
\hline $135 \mathrm{~V}^{\text {rd }}$ & 448 & 509 & 505 & 24.9 & 33.7 \\
\hline $180 \mathrm{~V}$ 3rd & 439 & 530 & 519 & 23.9 & 33.7 \\
\hline $\begin{array}{l}45 \mathrm{~V} 2^{\text {nd }} \\
45 \mathrm{~V} 3^{\text {rd }}\end{array}$ & 478 & 519 & 518 & 26.3 & 34.1 \\
\hline $\begin{array}{l}90 \mathrm{~V}^{\text {nd }} \\
45 \mathrm{~V} 3^{\text {rd }}\end{array}$ & 484 & 564 & 573 & 24.7 & 33.9 \\
\hline $\begin{array}{l}110 \mathrm{~V}^{\text {nd }} \\
45 \mathrm{~V}^{\text {rd }}\end{array}$ & 489 & 579 & 602 & 23.7 & 33.9 \\
\hline $\begin{array}{l}45 \mathrm{~V} 2^{\text {nd }} \\
90 \mathrm{~V} 3^{\text {rd }}\end{array}$ & 483 & 541 & 541 & 25.8 & 33.9 \\
\hline $\begin{array}{l}90 \mathrm{~V} 2^{\text {nd }} \\
903^{\text {rd }}\end{array}$ & 494 & 582 & 599 & 24.5 & 34.0 \\
\hline
\end{tabular}



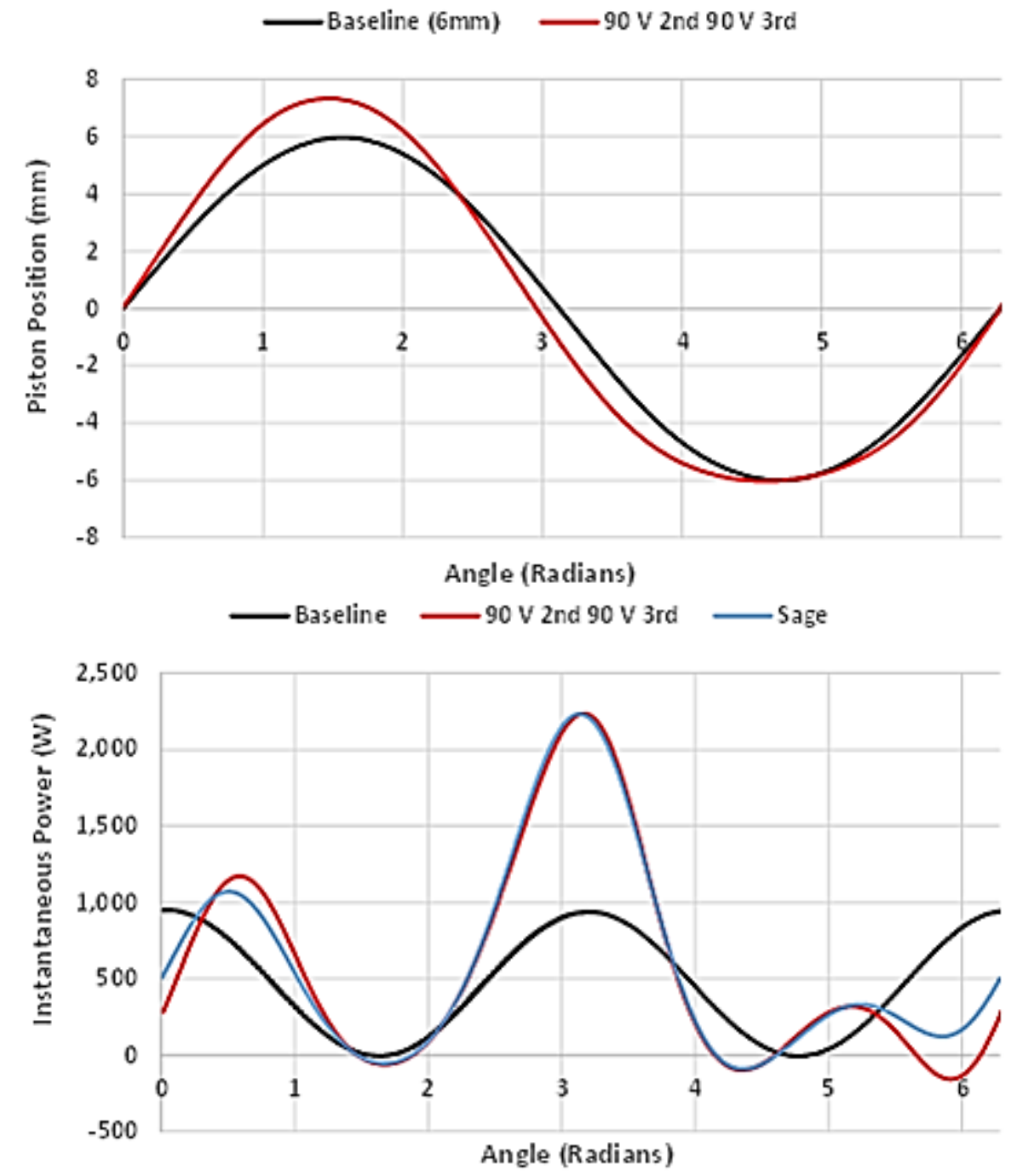

Figure 5.-Comparison of sinusoidal and non-sinusoidal waveforms and instantaneous power.

Table III shows that thermodynamic power calculated using the current and estimated EMF is in good agreement with Sage predictions. Thermodynamic power, as measured by adding resistive losses to the power at the alternator leads is consistently lower than the Sage predictions and the calculation based on EMF. The power measured at the terminals is considered the more direct measurement and is therefore used as the figure of merit in this paper. Figure 5 compares sinusoidal motion versus a case that includes the second and third harmonics. Measured piston position is compared to the sinusoidal case and instantaneous power calculated from the EMF is compared to the sinusoidal case and to Sage predictions.

\subsection{Discussion}

This experiment shows that second and third harmonic waveforms can be superimposed on the single harmonic piston waveforms typically used on Stirling engines. Higher harmonic waveforms with correct phasing are shown to increase thermodynamic power. The engines chosen for testing (and the vast majority of free-piston Stirling engine designs) have no mechanism available for controlling displacer motion, so optimized displacer waveforms could not be imposed, and displacer amplitude could not be 
limited. The resulting free-displacer motion is very close to sinusoidal and in many cases increases the out-limit of displacer motion during higher harmonic testing beyond the out-limit of displacer motion measured during the sinusoidal baseline test. Therefore, the increase in piston power measured during this test does not necessarily prove an increase in power density because the engine would have to grow to accommodate the displacer motion. Furthermore, since increased displacer amplitude can lead to increased power output in the absence of changes to the piston waveform, it is not clear how much of the power output increase measured during testing can be directly attributed to altering the piston waveforms and what portion should be attributed to the increase in displacer amplitude. However, since the displacer is a passive component driven by the pressure differential between the bounce space and the workings space, the increased amplitude is itself an indication of increased pressure forces and increased power output caused by higher harmonic piston motion.

The thermodynamic power, calculated by several methods described in Section 3.1, Methodology, is in close agreement with analytical results provided by the Sage nodal analysis tool. However, thermodynamic power calculated by adding resistive alternator losses to the measured alternator power is consistently lower than calculated values and Sage predictions. This could be an indication of an inadequate alternator loss model or a breakdown of the assumptions going into the thermodynamic power calculations. Future work could address this discrepancy by developing a comprehensive alternator model and/or including a dynamic pressure measurement so that the thermodynamic power can be measured directly. In the event that future work shows Sage predictions and calculated thermodynamic power to be accurate, it will still be necessary to understand the loss mechanisms that prevent the thermodynamic power being measured at the alternator leads.

Numerical optimization, using the Sage nodal analysis tool, identifies a second piston position harmonic of $-\pi / 2$ and a third piston position harmonic phase angle of zero as producing the maximum increase in power output and were the only phase angles tested. Future work could identify other optimal waveforms based on other objective functions. Alternatively, a more Edisonian approach could be used in which the entire range of possible phase angles is explored, observing their effects on power density and efficiency. This method would eliminate the need for accurate nodal analysis.

Isothermal analysis of ideal engines shows that the use of ideal piston and displacer waveforms increases Stirling engine power density. The magnitude of the increase depends on the method of constraint, but is found, in all cases to be proportional to the natural logarithm of the working space volume ratio. Isothermal analysis of a specific engine design including dead volume has previously shown that Stirling engines operating with ideal piston and displacer waveforms could increase power output 50 to 315 percent depending on the method of constraint as shown in Reference 25. Nodal analysis shows that loss mechanisms not taken into account in isothermal analysis reduce the power output expected from ideal waveforms, often times below the power output expected from sinusoidal motion. Numerical optimization shows that piston and displacer waveforms that compromise between the benefits of ideal motion and the reduced losses of sinusoidal motion can be used to increase power output by as much as 58 percent, depending on the method of constraint. Experimental data shows that engines operating with same out-limit of piston motion can be made to produce as much as 14 percent additional thermodynamic power by superimposing a second and third harmonic on the original sinusoidal piston waveform.

\section{References}

1. G. Wood and N. Lane, "Advanced 35 W Free-Piston Stirling Engine for Space Power Applications,” in Space Technology and Applications International Forum (STAIF), 2003.

2. W. Martini, “Stirling Engine Design Manual 2nd Ed.,” NASA CR-168088, Cleveland, Ohio, 1983. 
3. I. Urieli and D. Berchowitz, Stirling Cycle Engine Analysis, Bristol: Adam Hilger, 1984.

4. J. Senft, "Drive mechanism for Stirling engine displacer and piston and other reciprocating bodies." United States Patent US 4339960 A, 30 June 1980.

5. A. Chertok, "Free Piston Stirling Engine Control”. US Patent US 7200994 B2, 1 July 2004.

6. J. Beggs, "Stirling cycle cryogenic cooler”. United States Patent US 4389849 A, 2 October 1981.

7. T. McWaters, "Kinematic Stirling Engine”. United States Patent US 5644917 A, 13 May 1996.

8. G. Mungas, "High Efficiency Energy Conversion”. United States Patent US 20120031091 A1, 3 August 2011.

9. D. Keiter, “Sunpower Cryotel Cryocoolers and Pulse Tube Crycoolers,” 2005. [Online]. Available: http://sunpowerinc.com/library/cryocooling/. [Accessed 23 January 2015].

10. "Free Piston Stirling Crycooler,” Janis, [Online]. Available: http://www.janis.com/Products/productsoverview/FreePistonStirlingCryocooler.aspx. [Accessed 29 January 2015].

11. Stirling Power, "Stirling Solutions in Renewable Power," Stirling Power, [Online]. Available: http://www.sp-usa.com/. [Accessed 26 January 2015].

12. Microgen, "Your Personal Power Plant,” Microgen, [Online]. Available: http://microgenengine.com/. [Accessed 261 2015].

13. “60 Years of Cryogenic Experience,” Stirling Cryogenics, [Online]. Available: http://www.stirlingcryogenics.com/. [Accessed 29 January 2015].

14. “United Sun Systems,” United Sun Systems, [Online]. Available: http://www.unitedsunsystems.com/. [Accessed 29 January 2015].

15. L. Mason, "Solar Stirling for Deep Space Applications,” NASA Glenn Research Center, Cleveland, 1999.

16. J. Stearns, “Solar Stirling Receiver Alternatives for the Terrestrial Solar Application,” Joint Propulsion Lab, Pasadena, 1986.

17. F. S. P. Team, "Fission Surface Power System Initial Concept Definition,” NASA, 2010.

18. L. Mason, L. Qualls and D. Poston, “System Concepts for Affordable Fission Surface Power,” NASA Glenn Research Center, Cleveland, 2008.

19. M. Gibson, L. Mason, C. Bowman, D. Poston, P. McClure, J. Creasy and C. Robinson, "Development of NASA's Small Fissoion Power System for Science and Human Exploration,” in Internation Energy Conversion Engineering Conference, Cleveland, 2014.

20. J. Schreiber, “Assessment of the Stirling Power Option for Space Science Applications,” in IEEE Aerospace Conference, Big Sky, 2000.

21. S. Wilson and W. Wong, "NASA Glenn Research Center Support of the ASRG Project," in AIAA Propulsion and Energy Forum, Cleveland, 2014.

22. W. Wong, S. Wilson and J. Collins, “Advanced Stirling Convertor Development for NASA RPS,” in AIAA Propulsion and Energy Forum, Cleveland, 2014.

23. L. Mason, “A Comparision of Fission Power Systems Options for Lunar and Mars Surface Applications,” in Space Technology and Applications International Forum, Albuquerque, 2006.

24. G. Schmidt, "The Theory of Lehmann's Calorimetric Machine,” 1871.

25. M. Briggs “Improving Free-Piston Stirling Engine Power Density” Ph.D. dissertation, Mechanical Engineering Dept, Case Western Reserve University, Cleveland, OH 2015.

26. D. Gedeon, “Sage User's Guide,” 20 June 2014. [Online]. Available: http://www.sageofathens.com/Documents/SageStlxHyperlinked.pdf. [Accessed 15 April 2015].

27. M. Briggs, S. Geng, J. B. Pearson and T. Godfroy, "Summary of Test Results from a 1kWe-Class FreePiston Stirling Power Convertor Integrated with a NaK Pumped Loop,” NASA, Cleveland, 2010.

28. M. Briggs, "Dynamic Behavior of Kilowatt Class Stirling Convertors with Coupled Expansion Spaces,” in Nuclear and Emerging Technologies for Space (NETS), Albuquerque, 2012. 

